\title{
The catastrophic 1883 earthquake at the island of Ischia (southern Italy): macroseismic data and the role of geological conditions
}

\author{
S. Carlino $\cdot$ E. Cubellis $\cdot$ A. Marturano
}

Published online: 2 April 2009

(C) Springer Science+Business Media B.V. 2009

\section{Erratum to: Nat Hazards}

DOI 10.1007/s11069-009-9367-2

Due to a technical error, Fig. 4 has been set wrongly. The reader can find the right figure in the following page.

The online version of the original article can be found under doi:10.1007/s11069-009-9367-2.

S. Carlino $(\bowtie) \cdot$ E. Cubellis · A. Marturano

Istituto Nazionale di Geofisica e Vulcanologia (INGV), Sezione di Napoli Osservatorio Vesuviano,

Via Diocleziano 328, 80124 Naples, Italy

e-mail: carlino@ov.ingv.it 


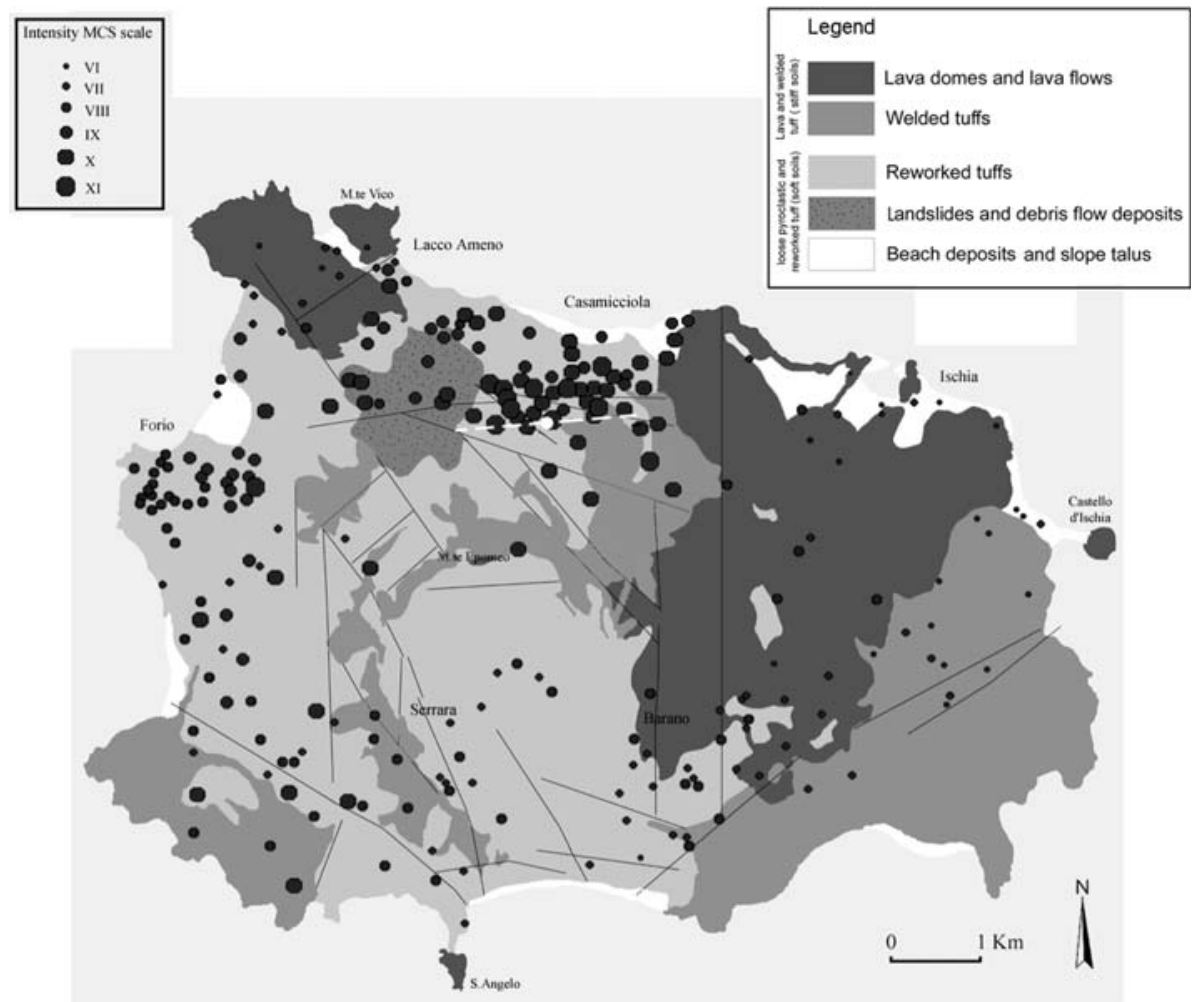

Fig. 4 Geological sketch map of the island and distribution of the intensity data of the 1883 earthquake inferred from the analysis of damage for 249 localities (from Cubellis et al. 2004). The dotted line represents the causative fault of the earthquake, the white point in the middle is the macroseismic epicentre 